\title{
Synthesis of Methyl 6-Deoxy-6-diphenylphosphino- $\alpha$-D-glucopyranoside: Temperature-Dependence of the Primary O-Tosyl Cleavage Mode
}

\author{
Wilhelm V. Dahlhoff*, Karin Radkowski \\ Max-Planck-Institut für Kohlenforschung, Kaiser-Wilhelm-Platz 1, \\ D-45466 Mülheim an der Ruhr \\ Z. Naturforsch. 51b, $891-896$ (1996); received November 29, 1995 \\ Carbohydrates, Carbohydrate-Phosphines, O-Tosyl Cleavage (C-O/S-O), \\ Chiral Phosphine Ligand \\ Methyl $\alpha$-D-glucopyranoside is converted to methyl 6 - $p$-toluenesulfonyl-2,3,4-tris-O-tri- \\ methylsilyl- $\alpha$-D-glucopyranoside $\mathbf{2}$ and then reacted with lithium diphenylphosphide in THF. \\ When the reaction is carried out at room temperature and below, $\mathrm{S}-\mathrm{O}$ cleavage dominates \\ giving methyl 2,3,4-tris-O-trimethylsilyl- $\alpha$-D-glucopyranoside $\mathbf{3}$, whereas at $60^{\circ} \mathrm{C}$ in $\mathrm{THF}$ or \\ at $35^{\circ} \mathrm{C}$ in diethyl ether, $\mathrm{C}$-O cleavage occurs yielding the title carbohydrate-phosphine 4 in \\ good yield after deprotection.
}

\section{Introduction}

The interest in water-soluble phosphines has risen dramatically since Kuntz pioneered the use of water-soluble rhodium complexes having sulfonated phosphine ligands in the Ruhrchemie/ Rhône-Poulenc hydroformylation process [1a]. The separation of the water-soluble catalyst from the lipophilic products is so effective that the rhodium losses are only $<10^{-9} \mathrm{~g}$ Rhodium $/ \mathrm{kg}$ of $n$-butanal [1b]. Apart from sulfonation, the other main approaches for obtaining water-soluble phosphines include the introduction of the most common hydrophilic groups such as carboxyl, hydroxyl, ethylene glycol or ammonium substituents [2].

Although there have been numerous reports of the synthesis of protected carbohydrate- phosphines[3], hitherto only one paper describes the attempt to prepare deprotected carbohydratephosphines $[3 \mathrm{~g}]$. The removal of the O-isopropylidene groups requires acidic conditions and this can cause difficulties in the presence of the basic phosphine moiety. Hence, the first reported deprotection of DIOP using hydrochloric acid in methanol/ water gave impure product [4]. Kagan et al. [3i] only recently showed that methanesulfonic acid is a better catalyst for the hydrolysis of the DIOP

\footnotetext{
* Reprint requests to Dr. W. V. Dahlhoff.
}

O-isopropylidene group and that purification by column chromatography is required. A pure dihydroxydiphosphine product is obtained from (S,S)-1,2:3,4-diepoxybutane, as no deprotection is needed [5].

In a project concerned with the synthesis of chiral water-soluble ligands, in particular phosphinemodified cyclodextrins [6], simple model carbohydrate phosphines were also prepared.

Below we report on the results obtained during work dealing with the convertion of methyl $\alpha$-Dglucopyranoside, which served as a cyclodextrin model, to methyl 6-deoxy-6-diphenylphosphino- $\alpha$ D-glucopyranoside.

\section{Results and Discussion}

Methyl $\alpha$-D-glucopyranoside was first converted to methyl 6-O-tosyl- $\alpha$-D-glucopyranoside $\mathbf{1}$ by treatment with tosyl chloride, in a reaction which was not as selective as expected [7].

As some mode of protection for $\mathbf{1}$ was required [10], O-trimethylsilyl protection was chosen, because this group is readily introduced and removed under slightly acidic conditions [12]. Previously $\mathrm{OSiMe}_{3}$ protection had been successfully used in an extremely efficient synthesis of 1-[1,7-dicarba-closo-dodecaboran(12)-1-yl]- $\alpha, \beta$-Dglucose by reaction of monolithiated $m$-carborane with 2,3,4,6-tetra-O-trimethylsilyl-D-glucono-1,5lactone [13]. 
<smiles>CO[C@H]1O[C@H](C)[C@@H](O)[C@H](O)[C@H]1O</smiles>

1

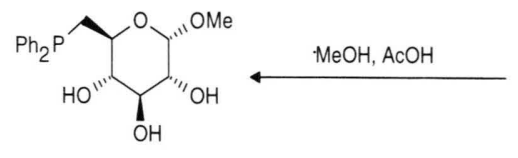

5

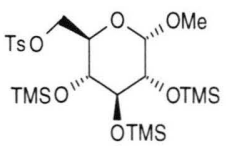

2

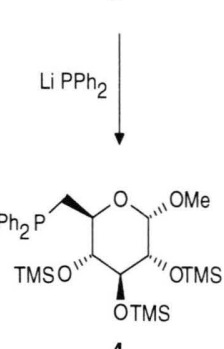

4

Scheme 1. Reaction scheme: conversion of $\mathbf{1}$ to $\mathbf{5}$.

Per-O-trimethylsilylation of $\mathbf{1}$ to give $\mathbf{2}$ in $c a$. $90 \%$ yield was achieved with a 2:1 mixture of hexamethyldisilazane and chlorotrimethylsilane [14]. The reaction of $\mathbf{2}$ with two equivalents of lithium diphenylphosphide was first attempted at $0{ }^{\circ} \mathrm{C}$, since it was feared that cleavage of the $\mathrm{OSiMe}_{3}$ group might occur to give O-lithiated derivatives of $\mathbf{1}$ and trimethylsiyl-diphenylphosphide. ${ }^{31} \mathrm{P}$ NMR of the crude product mixture after hydrolysis revealed that tetraphenyldiphosphine was the major P-containing product and that only $c a$. $23 \%$ of the desired methyl 6-deoxy-6-diphenyl-

phosphino-2,3,4-tris-O-trimethylsilyl- $\alpha$-D-glucopyranoside $\mathbf{4}$ had been formed, evidently because of S-O cleavage of the tosyl group [15].

Lowering the reaction temperature to $-20^{\circ} \mathrm{C}$, resulted in a drop in the amount of $\mathbf{4}$ to only $10 \%$ with a concomittant increase in the proportion of tetraphenyldiphosphine. The NMR and mass spectra reveal that S-O cleavage of the O-tosyl group is the dominant reaction, resulting in the formation of the known methyl 2,3,4-tris-O-trimethylsiyl- $\alpha$-D-glucopyranoside $\mathbf{3}$ [18].

The chemical shift of C-6 at 60.9 is in the characteristic range for the carbon atom of a free primary hydroxyl group [19] and the mass spectrum has a $m / z=395$, which is due to M-Me.

However, it is somewhat surprising that when the lithium diphenylphosphide is added dropwise to 2 at $60^{\circ} \mathrm{C}$, the desired sugar-phosphine $\mathbf{4}$ becomes the major product with only $10 \%$ of tetraphenyl-diphosphine in the reaction mixture.

Orientational experiments [20] with 6-O-tosyl1,2:3,4-di-O-isopropylidene- $\alpha$-D-galactopyranose had shown that the amount of lithium diphenylphosphide can be almost halved when carrying out the reaction in diethyl ether rather than tetrahydrofuran. This enabled the synthesis of 6-deoxy6-diphenylphosphino-1,2:3,4-di-O-isopropylidene$\alpha$-D-galactopyranose in $c a$. $80 \%$ yield.<smiles>CO[C@H]1[C@@H](OC)[C@H](OC)[C@@H](COS(=O)(=O)c2ccc(C)cc2)O[C@H]1OC</smiles>
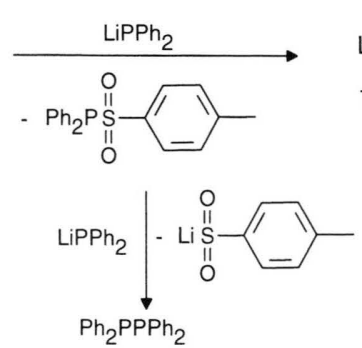<smiles>CCO[C@H]1O[C@H](OC)[C@@H](OC)[C@H](OC)[C@H]1OC</smiles>

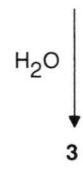

Scheme 2. Possible $\mathrm{S}-\mathrm{O}$ cleavage mode of $\mathbf{2}$ by $\mathrm{LiPPh}_{2}$ leading to $\mathbf{3}$ and $\mathrm{Ph}_{2} \mathrm{PPPh}_{2}$.

Table I. Reaction of $\mathbf{2}$ with $\mathrm{LiPPh}_{2}$ at various temperatures.

\begin{tabular}{lllcccc}
\hline $\mathbf{2}[\mathrm{mmol}]$ & Solvent & Molar ratio $\mathbf{2 :} \mathrm{LiPPh}_{2}$ & Temperature $\left[{ }^{\circ} \mathrm{C}\right]^{\mathrm{b}}$ & Time $[\mathrm{h}]$ & $\mathbf{4}^{\mathrm{a}}$ & $\mathrm{Ph}_{2} \mathrm{PPh}_{2}{ }^{\mathrm{a}}$ \\
\hline 1 & THF & $1: 2$ & 0 & 1 & $\sim 23$ & $\sim 77$ \\
0.7 & THF & $1: 2$ & -20 & 3 & $\sim 10$ & $\sim 90$ \\
3.5 & THF & $1: 2$ & 60 & 1 & $\sim 90$ & $<10$ \\
\hline
\end{tabular}

${ }^{\text {a }}$ Amounts of $\mathbf{4}$ and $\mathrm{Ph}_{2} \mathrm{PPPh}_{2}$ estimated by ${ }^{31} \mathrm{P}$ PMR after hydrolysis: $\mathbf{4} \delta-20.2, \mathrm{Ph}_{2} \mathrm{PPPh}_{2} \delta-14.3$; ${ }^{\mathrm{b}}$ bath temperature. 
In the case of $\mathbf{2}$, the use of diethyl ether as a solvent also allowed a reduction in the amount of lithium diphenylphosphide required for complete reaction of the starting tosylate. The reaction of $\mathbf{2}$ with lithium diphenylphosphide in the ratio $1: 1.2$ gave 4 in high yield, with only $6 \mathrm{~mol} \%$ of tetraphenyldiphosphine side-product being present in the crude product.

Deprotection of $\mathbf{4}$ was achieved with acidic methanol at room temperature, giving waxy $\mathbf{5}$ in ca. $90 \%$ yield. The ${ }^{31} \mathrm{P}$ NMR chemical shifts of both $\mathbf{4}$ and $\mathbf{5}$ are at $c a$. -20 . These values are close to those found for DIOP and 2,3-dihydroxy-1,4bis(diphenylphosphino)-butane [4]. Hence, in these cases deprotection does not result in a remarkable low-field shift in the ${ }^{31} \mathrm{P}$ NMR spectra, as reported recently for two carbohydrate-phosphines $[3 \mathrm{~g}]$.

\section{Experimental}

All experiments were carried out in dry deoxygenated solvents under argon.-MS: Finnigan MAT CH5. $-{ }^{1} \mathrm{H},{ }^{13} \mathrm{C}$ and ${ }^{31} \mathrm{P}$ NMR: Bruker AC-200, AMX-400. The ${ }^{31} \mathrm{P}$ NMR shifts are given in $\delta$ relative to external $85 \%$ phosphoric acid. Other chemical shifts are given relative to TMS.

\section{Starting compounds}

Methyl $\alpha$-D-glucopyranoside was purchased from Fluka. Lithium diphenylphosphide was prepared by reaction of butyl lithium with diphenylphosphine (both obtained from Aldrich) in hexane at room temperature as described below.

\section{HPLC conditions}

For analytical measurements at $35^{\circ} \mathrm{C}$-Varian 5060, Shimadzu CTO-6A, Varian UV 100. Stationary phase: $250 \mathrm{~mm}$ Nucleosil $100-5-\mathrm{C}_{18} / \mathrm{A}, 4.5 \mathrm{~mm}$ internal diameter. Mobile phase: acetonitrile/ water 30:70-10 min-80:20-10 min isocratic 80:20. Flow rate $0.8 \mathrm{ml} / \mathrm{min}$ with $10.6 \mathrm{Mpa}$. Preparative conditions at room temperature.- Instrument: Shimadzu LC-8 gradient system.-Column: $230 \mathrm{~mm}$ Buchi MPLC, $36 \mathrm{~mm}$. Stationary phase: LiChroprep Si 100-C18/Cl, 25-40 $\mu \mathrm{m}$. Mobile phase: acetonitrile/water 60:40 for isolation of the ditosyl compound and 25:75 for isolation of the monotosylated compounds. Flow rate $20 \mathrm{ml} / \mathrm{min}$ at 1.4 MPa. Detection: UV, $238 \mathrm{~nm}$.

\section{Lithium diphenylphosphide}

A $1.6 \mathrm{~m}$ solution of butyl lithium $(80 \mathrm{ml}, 128$ mmol) is added dropwise in $c a .1 .5 \mathrm{~h}$ to a stirred solution of diphenylphosphine $(20.5 \mathrm{~g}, 110 \mathrm{mmol})$ in hexane $(350 \mathrm{ml})$, so that the flask temperature does not exceed $38^{\circ} \mathrm{C}$. After stirring overnight, the lithium diphenylphosphide is filtered off, washed with hexane and dried in vacuo $\left(10^{-3}\right.$ Torr $)$ to give yellow, powdery product $(19.5 \mathrm{~g}, 92 \%) .{ }^{31} \mathrm{P}$ NMR (THF): $\delta=-20.7$.

\section{Methyl 6-O-p-toluenesulfonyl- $\alpha$-D-glucopyrano- side $(\mathbf{1})$}

A solution of $p$-toluenesulfonyl chloride $(10.5 \mathrm{~g}$, $55.1 \mathrm{mmol})$ in pyridine $(20 \mathrm{ml})$ is added dropwise to a stirred solution of methyl $\alpha$-D-glucopyranoside $(10 \mathrm{~g}, 51.5 \mathrm{mmol})$ in pyridine $(20 \mathrm{ml})$ at room temperature so that the flask temperature reaches $35^{\circ} \mathrm{C}$. The clear, yellow solution is stirred for $2 \mathrm{~d}$ at room temperature and then concentrated in vacuo ( $10^{-3}$ Torr, $60-70^{\circ} \mathrm{C}$ bath temperature). The residue is dissolved in chloroform $(25 \mathrm{ml})$ and the so-

\begin{tabular}{|c|c|c|c|c|}
\hline $\begin{array}{l}\text { Com- } \\
\text { pound }\end{array}$ & $\begin{array}{l}\text { Formula } \\
\text { [mol. mass] }\end{array}$ & $\begin{array}{l}\text { Founc } \\
\text { M }\end{array}$ & $\begin{array}{l}\text { rel. intensity) } \\
\text { Base mass }\end{array}$ & Other characteristic masses \\
\hline 1 & $\begin{array}{l}\mathrm{C}_{14} \mathrm{H}_{20} \mathrm{O}_{8} \mathrm{~S} \\
{[348.4]}\end{array}$ & b & $60^{c}$ & $\begin{array}{l}317(<1), 245(19), 215(14) \\
173(14), 133(24), 91(64)\end{array}$ \\
\hline 2 & $\begin{array}{l}\mathrm{C}_{23} \mathrm{H}_{44} \mathrm{O}_{8} \mathrm{SSi}_{3} \\
{[564.9]}\end{array}$ & $\begin{array}{l}564 \\
(<1)\end{array}$ & 204 & $\begin{array}{l}533(<1), 459(<1), 443(1) \\
317(26), 287(7), 217(30)\end{array}$ \\
\hline 3 & $\begin{array}{l}\mathrm{C}_{16} \mathrm{H}_{38} \mathrm{O}_{6} \mathrm{Si}_{3} \\
{[410.7]}\end{array}$ & - & 204 & $\begin{array}{l}395(<1), 379(<1), 305(2) \\
290(4), 276(3), 217(48)\end{array}$ \\
\hline 4 & $\begin{array}{l}\mathrm{C}_{28} \mathrm{H}_{47} \mathrm{O}_{5} \mathrm{PSi}_{3} \\
{[578.8]}\end{array}$ & $\begin{array}{l}578 \\
(1)\end{array}$ & 73 & $\begin{array}{l}563(7), 547(2), 488(17) \\
317(12), 243(23), 204(45)\end{array}$ \\
\hline 5 & $\begin{array}{l}\mathrm{C}_{19} \mathrm{H}_{23} \mathrm{O}_{5} \mathrm{P} \\
{[362.4]}\end{array}$ & $\begin{array}{l}362 \\
(5)\end{array}$ & 186 & $\begin{array}{l}347(5), 331(3), 302(12) \\
285(40), 199(22), 108(56)\end{array}$ \\
\hline
\end{tabular}

Table II. Formulae and mass spectrometric data of 1-5.

\footnotetext{
a EI-MS (70 eV); b $\left[\mathrm{M}+\mathrm{NH}_{4}\right] 366$ found by $\mathrm{CI}$ with ammonia as the reactant gas; c above $140{ }^{\circ} \mathrm{C}$ decomposition occurs and the mass spectrum of $p$-toluenesulfonic acid is obtained.
} 
lution is washed with saturated potassium hydrogen sulfate $(10 \mathrm{ml})$ and potassium hydrogen carbonate $(10 \mathrm{ml})$. The solid obtained after removal of the chloroform is treated with ethanol $(10 \mathrm{ml})$ and dried in vacuo $\left(10^{-3}\right.$ Torr, $<40{ }^{\circ} \mathrm{C}$ bath temperature) to give a white, amorphous solid mixture $(12.3 \mathrm{~g})$, which contains $46 \% \mathbf{1}, 7 \%$ methyl 2-O- $p$-toluenesulfonyl- $\alpha$-D-glucopyranoside and $31 \%$ methyl 2,6-di-O- $p$-toluenesulfonyl- $\alpha$-D-glucopyranoside (HPLC analysis). Preparative HPLC separation yields $99.9 \%$ pure $1(4.7 \mathrm{~g}, 26 \%)$ with m.p. $130^{\circ} \mathrm{C}$ (Lit.[8] $124^{\circ} \mathrm{C}$ ) and $[\alpha]_{\mathrm{D}}^{20} 100.7$ (c 0.6, $\mathrm{MeOH})$. The 2-O-tosyl isomer $(0.5 \mathrm{~g}, 2.7 \%)$ and the 2,6-di-O-tosyl derivative $(2.05 \mathrm{~g}, 8 \%)$ are also separated. The ditosylated compound can also be removed from the mixture by flash chromatography (silica gel, ethyl acetate).

Methyl 2,3,4-tris-O-trimethylsilyl-6-O-p-tolylsulfonyl- $\alpha$-D-glucopyranoside (2)

A solution of $\mathbf{1}(4.7 \mathrm{~g}, 13.5 \mathrm{mmol})$ in pyridine $(30 \mathrm{ml})$ is treated with hexamethyldisilazane $(11.3$ $\mathrm{ml}, 54.2 \mathrm{mmol}$ ) and trimethylsilyl chloride $(3.4 \mathrm{ml}$, $27 \mathrm{mmol}$ ) is added dropwise to the stirred mixture at $0^{\circ} \mathrm{C}$. After $15 \mathrm{~min}$. at $0{ }^{\circ} \mathrm{C}$ the mixture is stirred for $1 \mathrm{~h}$ at room temperature before adding pentane $(\mathrm{ca} .30 \mathrm{ml})$, filtering and concentrating the filtrate in vacuo $\left(10^{-3}\right.$ Torr, $<60^{\circ} \mathrm{C}$, bath). 2 (6.82 $\mathrm{g}, 89 \%$ ) is obtained as a colourless, highly viscous residue.

Methyl 2,3,4-tris-O-trimethylsilyl- $\alpha$-D-glucopyranoside $\mathbf{3}$ by reaction of $\mathbf{2}$ with lithium diphenylphosphide at $0{ }^{\circ} \mathrm{C}$

A solution of $2(0.55 \mathrm{~g}, \sim 1 \mathrm{mmol})$ in THF (10 $\mathrm{ml})$ is added dropwise to lithium diphenylphosphide $(2 \mathrm{mmol})$ in $\mathrm{THF}(5 \mathrm{ml})$ at $0{ }^{\circ} \mathrm{C}$ (bath). The mixture is stirred for $1 \mathrm{~h}$, at which time the bath temperature has risen to $10^{\circ} \mathrm{C}$ and TLC (diethyl ether / hexane 1:1) indicates that no more $\mathbf{2}$ is pre- sent. Diethyl ether $(10 \mathrm{ml})$ is added and the organic solution is washed with ice-water and then evaporated to dryness to give a P-containing mixture containing $\sim 23 \% \quad 4$ and $77 \%$ tetraphenyldiphosphine (by ${ }^{31} \mathrm{P}$ NMR) together with $\mathbf{3}$.

A similar experiment carried out at $-20^{\circ} \mathrm{C}$ bath temperature for $3 \mathrm{~h}$ gives a mixture of P-containing products with only $\sim 10 \% \quad \mathbf{4}$ and $90 \%$ $\mathrm{Ph}_{2} \mathrm{PPPh}_{2}$ (by ${ }^{31} \mathrm{P} \mathrm{NMR}$ ).

When the experiment is carried out at $60{ }^{\circ} \mathrm{C}$ for $1 \mathrm{~h} \sim 90 \% \quad 4$ and $\leq 10 \% \mathrm{Ph}_{2} \mathrm{PPPh}_{2}$ is obtained.

Methyl 6-Deoxy-6-diphenylphosphino-2,3,4-tris-Otrimethylsilyl- $\alpha-D$-glucopyranoside (4)

A solution of $2(1.2 \mathrm{~g}, 2.1 \mathrm{mmol})$ in diethyl ether $(10 \mathrm{ml})$ is added dropwise to a solution of lithium diphenylphosphide $(0.47 \mathrm{~g}, 2.45 \mathrm{mmol})$ in diethyl ether $(\sim 15 \mathrm{ml})$ at $45^{\circ} \mathrm{C}$ (bath temperature) and the stirred mixture is then heated under reflux. After $0.5 \mathrm{~h}, \mathbf{2}$ can still be detected by TLC (ether/ hexane 1:1) so a spatula tip of lithium diphenylphosphide is added and refluxing is continued for a further $0.5 \mathrm{~h}$. The ether solution is shaken with water and the organic phase is concentrated in vacuo $\left(10^{-3}\right.$ Torr $)$ to give $4(1.18 \mathrm{~g}, 97 \%)$ with ${ }^{31} \mathrm{P}$ NMR $\left(\mathrm{CDCl}_{3}\right): \delta=-20.2$. The crude product contains $c a .6 \mathrm{~mol} \%$ of diphenylphosphine $\left(\delta_{31_{\mathrm{P}}}=-39.7\right)$.

\section{Methyl 6-deoxy-6-diphenylphosphino- $\alpha$-D-gluco- pyranoside (5)}

Methanol $(10 \mathrm{ml})$ containing glacial acetic acid $(0.1 \mathrm{ml})$ is added to $4(2.8 \mathrm{~g}, 4.9 \mathrm{mmol})$ and the stirred mixture is heated under reflux for $6 \mathrm{~h}$. Crude 5 (1.8 g, 102\%) is obtained on removing the volatile components in vacuo $\left(10^{-3}\right.$ Torr, $60{ }^{\circ} \mathrm{C}$ bath temperature). 5 is treated with diethyl ether $(20 \mathrm{ml})$ and heated under reflux before adding ethanol $(\sim 2 \mathrm{ml})$ to obtain a clear solution. On

Table III. ${ }^{1} \mathrm{H}$ NMR chemical shifts and coupling constants (in parentheses) for the methyl $\alpha$-D-glucopyranosides $\mathbf{1}$, $\mathbf{2}$ and $\mathbf{5}$.

\begin{tabular}{|c|c|c|c|c|c|c|c|c|c|}
\hline $\begin{array}{l}\text { Com- } \\
\text { pound }\end{array}$ & $\begin{array}{l}\text { Solvent } \\
(\mathrm{MHz})\end{array}$ & $\begin{array}{l}\text { H-1 } \\
\left(J_{1,2}\right)\end{array}$ & $\begin{array}{l}\mathrm{H}-2 \\
\left(J_{2,3}\right)\end{array}$ & $\begin{array}{l}\text { H-3 } \\
\left(J_{3,4}\right)\end{array}$ & $\begin{array}{l}\mathrm{H}-4 \\
\left(J_{4.5}\right)\end{array}$ & $\begin{array}{l}\mathrm{H}-5 \\
\left(J_{5,6 \mathrm{a}}\right)\end{array}$ & $\begin{array}{l}\text { H-6a } \\
\left(J_{5,6 a}\right)\end{array}$ & $\begin{array}{l}\text { H-6b } \\
\left(J_{6 a, 6 b}\right)\end{array}$ & $\mathrm{OMe}$ \\
\hline 1 & $\begin{array}{l}\text { DMSO- } d_{6} \\
(400)\end{array}$ & $\begin{array}{l}4.28 \\
(3.7)\end{array}$ & $\begin{array}{l}3.21 \\
(9.5)\end{array}$ & $\begin{array}{l}3.41 \\
(8.8)\end{array}$ & $\begin{array}{l}3.07 \\
(10)\end{array}$ & $\begin{array}{l}3.56 \\
(1.9)\end{array}$ & $\begin{array}{l}4.28 \\
(6.3)\end{array}$ & $\begin{array}{l}4.12 \\
(-10.7)\end{array}$ & 3.23 \\
\hline 2 & $\begin{array}{l}\mathrm{CDCl}_{3} \\
(200)\end{array}$ & $\begin{array}{l}4.36 \\
(3.6)\end{array}$ & $\begin{array}{l}3.25 \\
(9.1)\end{array}$ & $\begin{array}{l}3.57 \\
(8.4)\end{array}$ & $\begin{array}{l}3.22 \\
(9)\end{array}$ & $\begin{array}{l}3.53 \\
(1.8)\end{array}$ & $\begin{array}{l}4.15 \\
(5.9)\end{array}$ & $\begin{array}{l}3.94 \\
(-10.5)\end{array}$ & 3.14 \\
\hline $\mathbf{5}^{\mathrm{a}}$ & $\begin{array}{l}\text { Pyridine }-\mathrm{d}_{5} \\
(400)\end{array}$ & $\begin{array}{l}5.03 \\
(3.7)\end{array}$ & $\begin{array}{l}4.11 \\
(9.6)\end{array}$ & $\begin{array}{l}3.94 \\
(8.9)\end{array}$ & $\begin{array}{l}4.42 \\
(10)\end{array}$ & $\begin{array}{l}4.31 \\
(2.4)\end{array}$ & $\begin{array}{l}3.33 \\
(10.4)\end{array}$ & $\begin{array}{l}2.59 \\
(-14.3)\end{array}$ & 3.38 \\
\hline
\end{tabular}

a Additional coupling constants: $J_{5, \mathrm{P}} 10, J_{6 \mathrm{a} . \mathrm{P}} 3.8, J_{6 \mathrm{~b}, \mathrm{P}} 2$. 


\begin{tabular}{lllllllll}
\hline $\begin{array}{l}\text { Com- } \\
\text { pound }\end{array}$ & Solvent & C-1 & C-2 & C-3 & C-4 & C-5 & C-6 & OMe \\
\hline $\mathbf{1}$ & DMSO-d $_{6}$ & 99.5 & 71.7 & 73.2 & 69.9 & 69.6 & 70.4 & 54.6 \\
$\mathbf{2}$ & $\mathrm{CDCl}_{3}$ & 99.4 & 73.3 & 74.8 & 69.4 & 71.9 & 69.2 & 54.7 \\
$\mathbf{3}$ & $\mathrm{CDCl}_{3}$ & 99.2 & $71.1^{\mathrm{a}}$ & $74.1^{\mathrm{a}}$ & $71.1^{\mathrm{a}}$ & $73.2^{\mathrm{a}}$ & 60.9 & 54.0 \\
$\mathbf{4}$ & $\mathrm{CDCl}_{3}$ & 99.4 & $73.7^{\mathrm{a}}$ & $74.7^{\mathrm{a}}$ & 76.6 & 69.4 & 32.3 & 54.5 \\
& & & & & $(7.1)$ & $(13.2)$ & $(13.7)$ & $(4.3)$ \\
$\mathbf{5}$ & Pyridine-d $_{5}$ & 101.1 & $73.5^{\mathrm{a}}$ & $74.9^{\mathrm{a}}$ & 76.7 & 70.6 & 32.2 & 54.7 \\
& & & & & $(7.0)$ & $(13.1)$ & $(14.0)$ & $(3.0)$ \\
\hline
\end{tabular}

Table IV. Characterstic ${ }^{13} \mathrm{C} \quad \mathrm{NMR}$ data for $\mathbf{1 - 5}$.

a Assignment may be interchanged; $J_{\mathrm{PC}}$ in brackets. cooling, a waxy precipitate of $\mathbf{5}$ is formed and this is filtered off and dried to give white 5 (1.57 g, $89 \%$ ) with ${ }^{31} \mathrm{P}$ NMR (pyridine- $\mathrm{d}_{5}$ ): $\delta=-19.8$. Attempts to obtain crystalline material from either diethyl ether, chloroform or hexane/ethanol always result in the formation of waxy product. 5 is poorly soluble in water $\left(0.234 \mathrm{~g} / 100 \mathrm{ml}, 20^{\circ} \mathrm{C}\right.$, i.e. $\sim 6.5 \mathrm{mmol} / \mathrm{l})$.
[1] a) E. G. Kuntz, CHEMTECH 570 (1987);

b) B. Cornils, E. Wiebus, ibid. 33 (1995).

[2] W. A. Herrmann, C. W. Kohlpaintner, Angew. Chem. 105, 1588 (1993) and references cited therein.

[3] a) J. Beněs, J. Hetflejš, Collect. Czech. Chem. Commun. 41, 2256 (1976);

b) D. Lafonte, D. Sinou, G. Descotes, J. Organomet. Chem. 169, 89 (1979);

c) H. Brunner, W. Pieronczyk, J. Chem. Research (M), 1251 (1980);

d) A. Aida, M. Yamashita, Bull. Chem. Soc. Jpn. 61, 2365 (1988);

e) T. H. Johnson, G. Rangarajan, J. Org. Chem. 45, 62 1980);

f) M. Yamashita, N. Suzuki, M. Yamada, M. Shibata, K. Serizawa, S. Inokawa, Carbohydr. Res. 99, C5-C8 (1982);

g) T. N. Mitchell, K. Heesche-Wagner, J. Organomet. Chem. 436, 43 (1992);

h) J. Bakos, B. Heil, L. Markó, ibid. 253, 249 (1983);

i) A. Börner, J. Ward, K. Kortus, H. B. Kagan, Tetrahedron: Asymmetry 4, 2219 (1993);

j) L. B. Fields, E. N. Jacobsen, ibid. 42229 (1993).

[4] R. Deschenaux, J. K. Stille, J. Org. Chem. 50, 2299 (1985).

[5] S. Zhang, S. Zhang, R. Feng, Tetrahedron: Asymmetry 2, 173 (1991).

[6] M. T. Reetz, J. Rudolph, Tetrahedron: Asymmetry 4, 2405 (1993).

[7] The selective O-tosylation of methyl $\alpha$-D-glucopyranoside at $0{ }^{\circ} \mathrm{C}$ has been reported to give methyl 6O-tosyl- $\alpha$-D-glucopyranoside in $55 \%$ yield without any chromatographic separation being required [8]. In our hands, the crude product which was obtained after extraction with chloroform, contained only $35 \% 2$, the main component being $43 \%$ methyl 2,6O-tosyl- $\alpha$-D-glucopyranoside together with $5 \%$ methyl 2-O-tosyl- $\alpha$-D-glucopyranoside as evidenced by analytical HPLC [9] and NMR spectroscopy. A better yield and distribution of products was obtained by adding the tosyl chloride in pyridine at such a rate, that the flask temperature rose to $35^{\circ} \mathrm{C}$ (see experimental section).

[8] F. D. Cramer, in R. L. Whistler, M. L. Wolfrom (eds): Methods in Carbohydrate Chemistry, Vol. 2, p. 244, Academic Press, New York, London (1963).

[9] We thank A. Deege and H. Hinrichs for the HPLC measurements and for the preparative separation of pure 2.

[10] In preliminary experiments with unprotected 6mono-6-O-tosyl- $\beta$-D-cyclodextrin, the reaction with potassium diphenylphosphide in the ratio $1: 1$ and with an excess of the phosphide was studied [11]. Hydroxy group deprotonation occurred in the 1:1 reaction, whereas the use of larger amounts of phosphide resulted in the formation of branched oligoand polyethers.

[11] a) J. Rudolph, Diplomarbeit, Univ. Bonn (1993);

b) J. Rudolph, Dissertation, Univ. Bochum (1995).

[12] a) E. Colvin, Silicon in Organic Synthesis, Butterworths (1981);

b) K. M. Taba, W.V. Dahlhoff, Synthesis 652 (1982).

[13] W.V. Dahlhoff, J. Bruckmann, K. Angermund, C. Krüger, Liebigs Ann. Chem. 1993, 831.

[14] D. Horton, W. Priebe, Carbohydr. Res. 94, 27 (1981).

[15] The S-O cleavage mode of O-tosyl groups has been used to prepare sulfones from sulfonic acid esters on reaction with alkyl lithium compounds in diethyl ether at room temperature [16]. A strong solvent effect is found in the reaction of 6-O-tosyl-1,2:3,4di- O-isopropylidene- $\alpha$-D-galactopyranose with lithium aluminium hydride. In THF, 1,2:3,4-di-Oisopropylidene- $\alpha$-D -galactopyranose is obtained after hydrolysis [17a], whereas in diethyl ether/benzene 1,2:3,4-di-O-isopropylidene- $\alpha$-D-fucose (6deoxy-D-galactose) is formed [17]. The reason for this strong solvent dependence is unknown.

[16] W. H. Baarschers, Can. J. Chem. 54, 3056 (1956).

[17] a) J. Lehmann, Chemie der Kohlenhydrate, p. 184, G. Thieme Verlag, Stuttgart (1976);

b) H. Schmid, P. Karrer, Helv. Chim. Acta 32, 1371 (1949). 
[18] a) D. J. Hurst, A. G. McInnes, Can. J. Chem. 43, [19] K. Bock, C. Pedersen, Carbohydr. Chem. Biochem. 2004 (1965);

41, 27 (1983).

b) M. Meldal, M. Christensen, K. Mette, K. Bock, [20] W. V. Dahlhoff, K. Radkowski, unpublished results. Carbohydr. Res. 235, 115 (1992). 